\title{
Avaliação Docente em Questão: tendências e estratégias
}

\author{
Ana Cristina Oliveira Leite Gonçalves ${ }^{1}$; Raimunda Tania Pinheiro de Oliveira ${ }^{2}$
}

\begin{abstract}
Resumo: Esse artigo tem por objetivo conhecer a política de avaliação docente, as leis que a regulamentam, os critérios utilizados para sua implantação e as implicações sobre os docentes e a carreira em si. Por meio de uma pesquisa bibliográfica acerca do tema, fundamentado em autores como: Mosé (2015), Gatti (2013), Bauer (2013), Danielson (2011) entre outros. O texto apresenta uma análise do que é avaliar, contextualizando com a avaliação docente, dentro dos propósitos somativos e formativos utilizados no processo avaliativo, na sequência, discute as propostas para a avaliação docente no Brasil, analisando documentos nacionais para identificar as estratégias e objetivos propostos.
\end{abstract}

Palavras-Chave: Professor. Avaliação docente. Política educacional.

\section{Evaluation Lecturer in question: trends and strategies}

\begin{abstract}
This article aims to understand the teacher evaluation policy, the laws that regulate the criteria used for its implementation and implications on the teachers and the career itself. Through a literature search on the subject, based on authors such as: Mosé (2015), Gatti (2013), Bauer (2013), Danielson (2011) among others. The paper presents an analysis of what is to evaluate, contextualizing with teacher assessment within the summative and formative purposes used in the evaluation process, following discusses proposals for teacher evaluation in Brazil, analyzing national documents to identify the strategies and objectives proposed.
\end{abstract}

Keywords: Teacher. teaching evaluation. Educational politics.

\section{Introdução}

Diante de algumas dificuldades educacionais públicas a qual vivencia-se atualmente e, observando o alto índice de alunos não alfabetizados na idade adequada, provenientes de um sistema educacional com diversos fatores críticos, contribuintes de forma direta para esse resultado, percebe-se a urgência de um sistema de avaliação docente. Tal iniciativa pode vir a garantir um melhor desempenho, evitando-se um déficit no crescimento intelectual e cultural do país, principalmente para aquela parcela da população, dependente da educação pública.

\footnotetext{
${ }^{1}$ Formada em História pela Universidade Regional do Cariri - URCA. Especialista em Planejamento e Politicas Educacionais pela URCA, Mestranda em Educação pela Anne Sullivan University. E-mail: crissoliver27@ outlook.com;

${ }^{2}$ Graduação em Ciências pela Universidade Regional do Cariri - URCA e Mestrado em Agronomia (Solos e Nutrição de Plantas) pela Universidade Federal do Ceará (2001). Atualmente é diretora administrativa da Fundação Escola de Educação Ambiental Mons. Murilo de Sá Barreto. Professora da Faculdades Integradas de Patos (FIP) e Universidade Estadual do Vale do Acaraú (UVA). E-mail: t.biologa@ gmail.com.
} 
Cristovam Buarque enaltece o poder da educação de qualidade para um país, quando afirma:

O que faz o país mudar não é o PIB subir, a taxa de analfabetismo cair, a taxa de jovens que terminam o Ensino Médio subir. É a capacidade dessas escolas de formarem um homem e uma mulher preparados para o mundo moderno, capazes de deslumbrar-se com a realidade, capazes de ter os instrumentos para transformar a realidade. A técnica, a ética e a estética. (BUARQUE,2015, p:177)

Cabe ressaltar que são inúmeras as dificuldades que os professores enfrentam no dia-adia: baixa remuneração, assédio moral, desvalorização, agressões, falta de profissionalismo, condições de trabalho precário, entre outras tantas. Porém, não justifica a falta de responsabilidade e compromisso com o ofício (independente do porquê da escolha), muito menos com os educandos que merecem uma oportunidade de transformarem o meio que vivem, através principalmente da educação.

Bauer (2013, p: 18) destaca que no Brasil se tem observado, recentemente, reflexos desse movimento mundial que coloca o professor como agente primordial para a melhoria da qualidade de ensino, devendo, portanto, ter seu trabalho e sua formação avaliados.

Nessa conjuntura, o professor é peça chave para a melhoria do ensino, assim sendo, fazse necessário a implantação de um processo de avaliação contínua dos docentes, observando pontos essenciais para excelência do desempenho profissional, entrevendo motivar a qualificação e melhoria das práxis pedagógicas, tanto individuais quanto coletivas.

Para efetuar essa pesquisa, objetivou-se conhecer as políticas públicas voltadas à avaliação dos docentes em exercício na rede pública de ensino, assim como os métodos utilizados para melhoria do processo ensino-aprendizagem.

\section{Avaliação Docente: Critérios}

Avaliar é atribuir valor. Todo processo avaliativo envolve escolhas e julgamentos, a partir de critérios que permitam traduzir valores considerados desejáveis [...] ato de reconhecer a qualidade, a importância ou a legitimidade de algo [...] sendo a valoração o processo desse reconhecimento (idem, p:21). 
A avaliação docente vem sendo, nesses últimos anos, bastante discutida, com o propósito de encontrar a forma mais adequada para avaliar competências e habilidades desejáveis a um bom professor, considerando aspectos sociais, históricos, culturais e econômicos que estão inseridos.

Sabe-se que a qualidade do processo de aprendizagem que ocorrem nas escolas, não são responsabilidade apenas do trabalho docente, mas, de todos aqueles que compõem a equipe escolar, sendo assim, imprescindível identificar o grau de contribuição que cada um exerce, visando um direcionamento mais eficaz de suas atribuições, visando a proficiência educacional, promovendo avaliações de desempenho, incentivando a busca de conhecimentos que venham a contribuir para melhorar sua ação no processo ensino-aprendizagem.

\begin{abstract}
Não adianta apenas aumentar os salários dos professores, não resolve ter escolas bem montadas com quadro digitais, na verdade nada resolve que não seja uma articulação de todos os aspectos e todas as necessidades, de modo que formem um corpo vigoroso e bem alimentado, um corpo vivo, aberto a mudanças, capaz de se relacionar com o entorno, a comunidade, a cidade, enfim, com o mundo. (MOSÉ, 2015, p: 72) grifo do autor.
\end{abstract}

Essa articulação envolve todos que possam fazer parte da aprendizagem do aluno, melhorando a qualidade da educação, brotando a vontade de fazer diferente, de buscar meios para que o objetivo final da escola seja atingido, criar homens críticos, pensantes, capazes de propiciar mudanças significativas na sociedade baseados em princípios éticos e políticos, mas, para isso, Dellanoy e Sedlacek (2000) apud Shiroma e Schneider (2011), ressaltam a necessidade de se produzir um novo tipo de professor, competente, eficaz, equipado com um amplo repertório de estratégias de ensino, profundo conhecimento de conteúdo e um novo conjunto de valores, enfatizando a colaboração entre pares, a reflexão contínua sobre sua prática de ensino e a capacidade de comunicar-se eficazmente.

O processo de avaliação docente, não deve ser visto como uma ação repressora, excludente ou discriminatória, mas como um mecanismo de melhorar a prática pedagógica dos professores e ampliação do conhecimento através de formações, criando uma dinâmica que cobre, responsabilize e fiscalize o ensino, através dessa avaliação impulsionando a qualificação docente, por conseguinte uma escola mais eficaz, com qualidade e responsabilidade social.

[...] avaliar construtivamente para o desenvolvimento formativo profissional constante é o contraponto. Avaliar por avaliar, avaliar para excluir ou punir, não leva a melhores resultados ao se considerar perspectivas de desenvolvimento humano e 
profissional [...] o foco central é criar alavancas para a construção de melhores condições pessoais, profissionais e de situações, etc. (GATTI, 2015, p.154)

Avaliação docente tem sido temática recorrente em escritos por diversos autores, referenciando formas e critérios usados no processo em vários países, com o propósito de melhorar o sistema educacional, conforme reforça Danielson:

\begin{abstract}
Os professores são importantes! A qualidade da educação a que estão expostos os alunos tem consequência duradoura para as perspectivas desses alunos. Portanto nenhuma nação comprometida com o crescimento econômico e acesso a ele por seus cidadãos pode ignorar o desafio de fortalecer a profissão docente. (DANIELSON, 2011,p.6).
\end{abstract}

Não é possível exigir qualidade no desempenho do professor, sem melhorar as condições de trabalho. A aprendizagem de fato ocorre com a sintonia entre as condições que a escola oferece ao aluno, como também ao docente para que exerça o seu ofício em ambiente e estrutura pedagógica adequada ao processo ensino-aprendizagem.

Outros aspectos, que influenciam o desempenho do professor, que não podem ser desprezados, nem tão pouco padronizados, são as "características socioeconômicas e culturais da clientela atendida, os diferentes níveis de habilidades e motivações dos estudantes, as múltiplas experiências pessoais dos discentes, a influência dos pais e demais professores naquele período ou momento anterior" (SILVA, MORICONI e GIMENES, 2013).

Avaliar o professor apenas em testes padronizados como ocorre no Brasil, levanta vários pontos a serem discutidos e revistos, para que se possa ter uma visão real do nível dos alunos, escolas e docentes dos componentes curriculares avaliados (essencialmente português e matemática).

A desigualdade socioeconômica é fator predominante no Brasil para o desempenho dos alunos. Como é possível padronizar os testes (Prova Brasil e SPAECE) em todo país, se temos uma disparidade econômica de uma região para outra? Como é possível avaliar de forma igualitária alunos de uma escola da capital e uma escola periférica de um município do interior, se vivem em realidades completamente diferentes? Será que o nível de informação dos professores são os mesmos em todas as regiões do país? As escolas possuem os mesmos mecanismos didáticos e apoio pedagógico especializado? São questionamentos de suma importância para a padronização no processo avaliativo tanto discente quanto docente. 
Outro fator grave, são as mudanças de foco do trabalho dos professores, enfatizando prioritariamente, conteúdos cobrados nas avaliações externas, direcionando o planejamento pedagógico para elaboração de projetos emergenciais, visando resultados imediatos, comprometendo o desenvolvimento dos alunos que serão avaliados, refletindo nos demais, ao serem excluídos desses projetos.

Diante do quadro diversificado de perspectiva e metodologias alternativas que visam correlacionar desempenho dos alunos e a ação escolar, torna-se necessário refletir como esses modelos são utilizados no âmbito prático das políticas pública em educação, seus potenciais riscos e alguns de seus possíveis efeitos na vida de professores e no cotidiano escolar. (Idem. p.89)

Essa política de avaliação pode favorecer a maquiagem dos resultados reais, sendo possível, enfatizar apenas dos componentes curriculares avaliados nos testes, intensificando o trabalho com descritores por iniciativa da escola ou da rede de ensino a que pertence, com o objetivo de elevar os índices.

Ainda pode-se evidenciar a falha na avaliação docente, através das avaliações externas, quando são avaliados apenas os professores de português e matemática, depositando nestes uma responsabilidade imerecida, tanto no fracasso quanto no êxito do processo avaliativo.

\section{Avaliação Docente: Propósitos}

Destacam-se dois propósitos para a avaliação docente, somativo e formativo, ambos importantes, porém com critérios diferentes, adequando-se aos objetivos avaliativos dos órgãos responsáveis pela rede de ensino avaliada.

A concepção mais tradicional de avaliação docente, se refere quase exclusivamente aos processos avaliativos ligado a seleção inicial de professor: avaliação do professor estagiário e certificação ou seleção de professores para contratação. Porém, aos poucos foi-se entendendo a importância da avaliação docente como meio para melhorar seu desenvolvimento profissional. Nessa perspectiva, a concepção inicial de avaliação era basicamente para verificar se o professor tinha os padrões mínimos, sendo uma avaliação de caráter somativo, atualmente numa perspectiva, onde o principal objetivo é ajudar o docente a melhorar seu desempenho, identificando os êxitos e detectando problemas, através da avaliação formativa para desempenho profissional. (TORRECILLA, 2007, p.87) tradução minha 
Em estudo desenvolvido por Bauer (2013), relacionam-se alguns propósitos somativos encontrados com mais frequência na literatura, que aborda a temática e outros formativos, justificados por países que utilizam esse tipo de avaliação.

\section{Propósitos Somativos}

Nessa perspectiva, os critérios de avaliação são voltados para assegurar a qualidade do ensino, tendo em vista, atingir o principal objetivo da escola, aprendizagem. Os principais propósitos destacados para esse tipo de avaliação conforme Bauer foram:

1. Selecionar docentes/contratação;

2. Concessão de licenças;

3. Certificação;

4. Aprimorar os indicadores de gestão;

5. Distinguir e premiar os melhores professores;

6. Decisões sobre penalidades (redução salarial, afastamentos, demissões, rebaixamento de cargos, etc.);

7. Seleção para formação continuada;

8. Decisões sobre benefícios (aumento salarial, promoção, pagamento por mérito, etc.);

9. Classificar docentes para fins de accontabilly.

\section{Propósitos Formativos}

Os propósitos formativos são direcionados para a melhoria da qualidade da educação, tendo em vista detectar e analisar os pontos fortes e fracos dos docentes, incentivando-os a sofisticar sua pratica através de formação profissional continuada. Bauer destaca os seguintes propósitos para esse tipo de avaliação:

1. Melhorar e assegurar a qualidade do ensino;

2. Fornecer informações a pesquisas avaliativas sobre ensino; 
3. Desenvolvimento de equipe - informação para basear as propostas de desenvolvimento profissional/ formação continuada;

4. Basear plano de desenvolvimento pessoal - identificar pontos fracos e áreas em que cada docente precisa investir;

5. Propiciar a autorreflexão do professor sobre seu trabalho (autoavaliação);

6. Acompanhar a prática docente visando sua melhoria;

7. Fornecer informações para conselhos escolares.

O processo de avaliação docente, muito complexo por envolver tanto a dimensão profissional como a organizacional da rede de ensino, não deve ser feito, utilizando apenas um tipo de avaliação, mas, combinar o somativo ao formativo. Para que a avaliação docente atinja de fato a que se propõem, é fundamental estabelecer padrões a serem avaliados e que esses, sejam definidos em debate, tendo a participação de professores, sindicatos, gestores, pais, alunos e membros do órgão gestor maior da rede de ensino que o docente faça parte. Torrecilla (2007) ratifica quando diz que,

Em primeiro lugar é necessário criar uma imagem construtiva da avaliação, numa abordagem de que está a favor do professor e de sua atuação profissional. Isso implica passar de um enfoque burocrático a outro mais profissional. Considerando que o sistema de avaliação de desempenho docente, deveria ser sempre precedido de um profundo debate e ser implementado apenas quando tenha uma aceitação geral pela comunidade educativa, principalmente os docentes. (TORRECILLA, 2007, p.34-3

Padrões de desempenho docente precisam descrever o que os professores devem saber e ser capazes de fazer em diferentes dimensões do seu trabalho ( NOVAES,2013), sendo necessários fazer algumas considerações ao serem determinados esses padrões, relacionados ao que está sendo avaliado: ingresso no sistema de ensino, avaliação de período probatório, progressão profissional, periocidade que ocorre para cada nível de ensino (infantil, fundamental, médio e superior, jovens e adultos) porque, cada seguimento de ensino requer prioridades diferenciadas, objetivos específicos, assim como o contexto e a cultura que produzem.

Novaes (2013) cita quatro etapas básicas para o desenvolvimento desses padrões: a) definir o que deve ser avaliado; b) decidir como será avaliado; c) identificar o que conta para 
atender o padrão; d) legitimar os padrões estabelecidos com diferentes representantes na área, e, posteriormente, com dados empíricos.

O processo de avaliação docente só é relevante para a educação, se for utilizado como forma de prestação de contas da ação educativa, servindo para lapidar o ensino, melhorando as práticas pedagógicas, impondo responsabilidades, propor incentivos e ascensão na carreira. Como disse Cristovam Buarque (2015), “ para ser um bom professor é necessário a Santíssima Trindade: cabeça (bem-informada), coração (bem-motivado) e bolso (bem-remunerado).

\section{Avaliação Docente no Brasil}

No Brasil fala-se de avaliação da docência desde a Constituição de 1934, quando estabelecia que o ingresso no magistério dar-se-ia através de concurso público, minimizando o clientelismo que existia na ocupação desses cargos, porém, apenas com propósitos somativos, medindo apenas o conhecimento e não as aptidões necessárias para um bom professor.

A proposta de um sistema federativo que certificasse as competências dos professores no Brasil, iniciou em 2001 com as Diretrizes Curriculares Nacionais para a Formação de Professores da Educação Básica. Em 2003, o Projeto de Lei nº 1.172, reitera a necessidade de construir bases sólidas e sistemáticas para a valorização do magistério, integradas e efetivas nos três níveis de sistema de ensino (BRASIL,2003).

Cristovam Buarque em 2003, como ministro da educação, institui o Sistema Nacional de Certificação e Formação Continuada de Professores, Portaria n ${ }^{\circ} 1.403$, propondo o “ Provão do Professor", que avaliaria conhecimentos e competências dos professores formados e formandos, tendo como objetivo avaliar os cursos de formação de professores, revogada em 2004, não chegando a ser realizada.

Em 2007, o Projeto de Lei (PL) $n^{\circ} 1.088$, pretendia alterar a Lei $n^{\circ}$ 9.394/96, estabelecendo como pré-requisito para a docência, a aprovação no Exame Nacional de Certificação. Segundo Gastão Vieira, autor do projeto, este seria “ um elemento adicional importante aos meios de recrutamento e seleção hoje existentes, em especial os concursos públicos [...] um marco de padrão de qualidade para o ingresso na carreira e induziria positivamente a melhoria da qualidade dos cursos de formação" (BRASIL, 2007). 
Ainda em 2007, através do PL n 403/2007, criou-se o Exame Nacional de Avaliação do Magistério da Educação Básica (ENAMEB), com o objetivo de avaliar o desempenho dos docentes de educação básica nas escolas públicas e privadas, estabelecia a participação voluntária e gratuita, podendo os resultados serem usados como avaliação de desempenho para fins de progressão na carreira do magistério pelos Estados, Municípios e Distrito Federal. O ENAMEB seria aplicado de 5 em 5 anos sucessivos na seguinte ordem: I - Docentes da Educação Infantil; II - Docentes dos anos iniciais do Ensino Fundamental ( $1^{\circ}$ ao $\left.5^{\circ}\right)$; IIIDocentes dos anos finais do Ensino Fundamental ( $6^{\circ}$ ao $\left.9^{\circ}\right)$; IV- Docentes do Ensino Médio; V- Docentes da Educação de Jovens e Adultos (EJA) e da Educação Especial (BRASIL, 2007a).

Em 2009, compilando os PLs $n^{\circ} 403 / 2007$ e o de $n^{\circ} 1.088 / 2007$, foi proposto em um novo PL de $n^{\circ} 6.114 / 2009$, sugerindo que o ENAMEB fosse prestado também para candidatos ao ingresso na docência, tendo como objetivo avaliar os conhecimentos ao invés de avaliar o desempenho, assim como não determinava como pré-requisito para exercício do magistério. No contexto final, não mudaria nada de expressivo no processo, continuava com caráter voluntário, e sem uma política de incentivo a participação.

Fernando Haddad, Ministro da Educação, em 2010, publicou uma Portaria Normativa $n^{\text {o }}$ 14/2010 de 21 de maio, instituindo o Exame Nacional de Ingresso a Carreira Docente, no âmbito do Instituto Nacional de Estudos e Pesquisas Educacionais Anísio Teixeira - INEP, para educação básica, com os seguintes objetivos, de acordo com o Art.2 $2^{\circ}$ :

I - subsidiar os Estados, o Distrito Federal e os Municípios na realização de concursos públicos para a contratação de docentes para a educação básica; II - conferir parâmetros para auto-avaliação dos futuros docentes, com vistas à continuidade da formação e à inserção no mundo do trabalho; III - oferecer um diagnóstico dos conhecimentos, competências e habilidades dos futuros professores para subsidiar as políticas públicas de formação continuada; IV - construir um indicador qualitativo que possa ser incorporado à avaliação de políticas públicas de formação inicial de docentes (BRASIL, 2010)

Dessa forma foi mais uma tentativa de avaliação dos docentes, inviabilizada, uma vez que permanece o caráter voluntário de participação, e dá a liberdade de escolher as cidades ou redes que preferissem trabalhar dentre os Municípios ou Estados que tivessem adesão ao Exame Nacional de Ingresso. De acordo com Shiroma e Schnneder...

[...] os professores poderão escolher as cidades ou redes em que pretendem trabalhar. A atratividade, no entanto, conforme destacado pela Confederação Nacional dos Trabalhadores em Educação, dependerá das ofertas de emprego público, quando os 
entes federados com os menores salários e/ou precárias condições de trabalho deverão encontrar dificuldades para atrair os professores melhor classificados no cadastro nacional do MEC. Cidades, estados e regiões mais ricas, que a priori pagariam melhores salários e ofereceriam maiores benefícios aos professores, certamente terão vantagem na competição pelos "melhores resultados" do cadastro nacional. (SHIROMA e SCHNNEDER, 2011, p.37)

Outro aspecto levantado pelas autoras supracitadas é que:

\begin{abstract}
Nesse sentido, o Exame de Ingresso do MEC poderá implicar a negociação salarial direta entre professor e secretarias de Educação, uma vez que essas podem utilizar o Exame de forma livre, escolhendo e captando os "melhores resultados", independentemente de seu portador e do local de origem desse. Igualmente, os professores podem escolher as melhores propostas salariais. Assim, é possível que essas se flexibilizem e os salários sejam diferenciados conforme a posição do candidato no ranking de classificação. A valorização dos professores, então, anunciada pelo MEC com a realização periódica do Exame, pode vir a depender prioritariamente de seu desempenho (idem, p.37).
\end{abstract}

Em 2011, o ministro Fernando Haddad, divulga Portaria Normativa ${ }^{\circ} 3$ de 2 de março de 2011, que instituía a “Prova Nacional de Concurso para Ingresso na Carreira Docente”, propondo a discussão das Matrizes de Referencias entre o MEC e as entidades educacionais que haviam manifestados várias questões preocupantes com o ENAMEB, a ANPAE Associação Nacional de Política e Administração da Educação); ANPEd ( Associação Nacional de Pesquisa e Pós-Graduação em Educação); CEDES (Centro de Estudos Educação e Sociedade; FORUMDIR ( Fórum Nacional de Diretores de Faculdades/Centros/Departamentos e Educação nas Universidades Públicas Brasileiras, além de consulta pública no website do MEC.

No Brasil, é comum a adoção de políticas de bonificação de professores, relacionadas a resultados obtidos pelas escolas, nas avaliações externas, sem considerar, critérios de avaliação diretamente relacionados aos professores nas suas áreas de atuação, como colaboradores na composição dos indicadores de sucesso escolar.

\title{
Considerações Finais
}

Existem muitos questionamentos relacionados a avaliação docente, no que se refere aos critérios avaliados e com que propósitos foram escolhidos, se foram determinados com ou sem a participação dos professores, gestores, comunidade, sindicatos e redes de ensino. 
De todo modo, independentemente dos aspectos, atributos ou dimensões a serem avaliados, e os critérios e indicadores que permitem mensurar as características desejáveis, cabe destacar que a discussão a ser realizada não é eminentemente técnica, mas é política, à medida que indica a necessidade de um ensino de qualidade (BAUER, 2013, p.32).

Embora a sociedade enxergue a necessidade de uma educação pública de qualidade, com professores qualificados, formadores dos profissionais das próximas gerações, de opinião, de cidadãos críticos com o poder de ler e transformar o mundo, deixa esse profissional a mercê do Estado, de políticas que o remetem simplesmente a funcionário público, vulneráveis as políticas convenientes aos governantes, muitas vezes cerceando de direitos uma vez adquiridos.

Para melhorar os indicadores da educação, o fato de avaliar o desempenho do professor, seja com propósitos somativos ou formativos, não garantirá uma educação de qualidade, se não tiver um planejamento educacional voltado para a valorização do magistério, deixando assim, de ser apenas uma questão técnica e burocrática para sobretudo política, optando por reformas que venham valorizar os professores.

\section{Referências}

BAUER, Adriana. Avaliação de desempenho de professores: pressupostos e abordagens. In: O trabalho docente: avaliação, valorização, controvérsias. Org: GATTI, Bernadete A. Campinas, São Paulo: Autores Associados, São Paulo: Fundação Carlos Chagas, 2013, p: 5-70.

BRASIL. Câmara dos Deputados. Comissão de Educação e Cultura. Raquel F. A. Teixeira. Projeto de Lei $\mathbf{n}^{\mathbf{0}} \mathbf{1 . 1 7 2 / 2 0 0 3}$. Dispõe sobre as diretrizes da política nacional de formação, certificação e valorização do magistério público.2003. Disponível em: http://www.camara.gov.br>. Acesso em: 11 de maio de 2016.

Câmara dos Deputados. Comissão de Educação e Cultura. Raquel F. A. Teixeira. Projeto de Lei $\mathbf{n}^{0}$ 1.088/2007. Altera a Lei $\mathrm{n}^{\circ}$ 9.394, de 20 de dezembro de 1996, para instituir o exame nacional de certificação como pré-requisito para o exercício do magistério na educação básica e dá outras providências. Disponível em: http://www.camara.gov.br/proposicoesWeb/fichadetramitacao?idProposicao=351844. Acesso em: 12 de maio de 2016.

Senado Federal. Wilson Matos. Projeto de Lei do Senado no 403, de 10 de julho de 2007. Institui o Exame Nacional de Avaliação do Magistério da Educação Básica (ENAMEB). 2007a.

Disponível em: 
http://www.senado.gov.br/atividade/materia/getPDF.asp?t=66073\&tp=1 Acesso em: 12 de maio de 2016.

Ministério da Educação. Gabinete do Ministro. Portaria Normativa no 14, de 21 de maio de 2010. Institui o Exame Nacional de Ingresso na Carreira Docente. Disponível em:http://sites.unasp.edu.br/portal/ secretariageral/ Documentos/BDE/2010-1/1220.pdf. Acesso em: 13 de maio de 2016.

BUARQUE, Cristovam. A escola e os desafios da inovação. Brasília. In: A escola e os desafios Contemporâneos / organização e apresentação. MOSÉ, Viviane. $4^{\mathrm{a}}$ ed. Rio de Janeiro: Civilização Brasileira, 2015. p: 161-180. Entrevista a Viviane Mosé.

DANIELSON, Charlote. Competencias docentes: desarrollo, apoyo y evaluación .Preal. Serie Documentos, Santiago, n. 51. Enero, 2011. Disponível em: $<$ http://preal.org/Archivos/Preal\%20Publicaciones/PREAL\%20Documentos/PREALDOC51. pdf $>$. Acesso em: 03 de abr 2016.

GATTI, Bernadete A. Valorização da docência e avaliação do trabalho docente: o papel da avaliação participativa em um contexto institucional. In: $O$ trabalho docente: avaliação, valorização, controvérsias. Org: GATTI, Bernadete A. Campinas, São Paulo: Autores Associados, São Paulo: Fundação Carlos Chagas, 2013, p: 153-176.

MOSÉ, Viviane. A escola e os desafios contemporâneos / organização e apresentação. $4^{\mathrm{a}}$ ed. Rio de Janeiro: Civilização Brasileira, 2015.

NOVAES, Glaucia Torres Franco. Padrões de desempenho na avaliação docente e profissionalidade docente. In: O trabalho docente: avaliação, valorização, controvérsias. Org: GATTI, Bernadete A. Campinas, São Paulo: Autores Associados, São Paulo: Fundação Carlos Chagas, 2013, p: 109-152

SHIROMA, Eneida Oto e SCHNEIDER, Mara Cristina. Professores em exame: reflexões sobre políticas de avaliação docente. Revista Práxis Educativa, Ponta Grossa, v. 6, n.1, p. 3144, jan-jun. 2011. Disponível em: <http://www.periodicos.uepg.br> Acesso em: 17 de mar 2016.

SILVA, Vandré Gomes da; MORICONI, Gabriela Miranda e GIMENES, Nelson Antonio Simão. Uso de resultados dos alunos em testes padronizados na avaliação docente: esclarecendo o debate. In: $O$ trabalho docente: avaliação, valorização, controvérsias. Org: GATTI, Bernadete A. Campinas, São Paulo: Autores Associados, São Paulo: Fundação Carlos Chagas, 2013, p:71-108.

TORRECILLA, F. Javier Murillo. Evaluación del desempeño y carrera profesional docente: un estudio comparado entre 50 países de América y Europa. Santiago, OREALC/UNESCO, 2007.Disponível em: http://unesdoc.unesco.org/images/0015/001529/152934s.pdf. Acesso em :21 de abr 2016. 


\section{Como citar este artigo (Formato ABNT):}

GONÇALVES, A.C.O.L.; OLIVEIRA, R.T.P. Avaliação docente em questão: tendências e estratégias. Id on Line Revista Multidisciplinar e de Psicologia, Set-Out de 2016, vol.10, n.31, Supl 2, p. 291-304. ISSN 19811179 .

Recebido: 12/09/2016

Aceito: 22/09/2016 